\title{
"Terrifying but Amazing": The Use of Supported Performance Simulation to Enhance Student Nurse's Ability to Learn and Articulate Ethically Sound Practice
}

\author{
By Amy Dopson* \\ Pat Colliety ${ }^{\dagger}$ \\ Stuart Andrewst \\ Teresa Hughes ${ }^{+}$ \\ Sharon Markless
}

\begin{abstract}
This paper discusses an illuminative evaluation of a collaborative series of workshops combining simulation, performance and reflection into supported performance simulation to explore challenging ethical scenarios. To explore the experiences of the theatre and child nursing students taking part in the workshops, to understand how they impacted on student's practice and to consider staff members' understanding of the value of this model of teaching and the potential for development. The experiences of those involved were explored, using focus groups and interviews within an illuminative evaluation approach. A purposive sample of the 19 nursing students, 10 theatre studies students and 4 teachers was used. We used interviews and focus groups as the method of the current study. Also, ethical approval and informed consent were gained. We found that four themes emerged from the data: the value of "real world experience"; increased confidence in dealing with ethically challenging situations; the development of "softer" skills and teaching and learning styles supporting reflective practice. The workshops enabled the nursing students to develop their communication skills, assertiveness and advocacy, whilst exploring ethically challenging situations. The use of performance simulation workshops allowed the nursing students to discover, test and reflect on their own and peers' practice in a safe environment. The workshops had increased their confidence in dealing with difficult ethical situations and enhanced their skills of assertiveness and advocacy.
\end{abstract}

Keywords: Caring behaviour, Ethical behaviour, Nurse education, Simulation, Theory-practice gap

\section{Introduction}

The fundamental importance of ethical practice in nursing was highlighted by the Francis report (The Mid Staffordshire NHS Foundation Trust 2013) and the 6 C's (Department of Health 2012) (Table 1), however teaching and exploring ethically sound practice in a realistic, safe environment remains challenging.

Table 1. The $6 C$ 's from the Francis Report

\begin{tabular}{|l|l|}
\hline 1. & Care \\
\hline 2. & Compassion \\
\hline 3. & Courage \\
\hline 4. & Commitment \\
\hline 5. & Competence \\
\hline 6. & Communication \\
\hline
\end{tabular}

\footnotetext{
* Senior Teaching Fellow, School of Health Sciences, University of Surrey, UK.

${ }^{\dagger}$ Senior Teaching Fellow, School of Health Sciences, University of Surrey, UK.

\$ Senior Lecturer, Department of Acting and Performance, GSA, University of Surrey, UK.

${ }^{+}$Teaching Fellow, School of Health Sciences, University of Surrey, UK.

'Senior Lecturer in Higher Education, King's Learning Institute, King's College London, UK.
} 
This paper discusses an initiative developed between child health teaching fellows and a theatre studies lecturer which, since 2009, has brought together students in child field nursing and theatre studies for collaborative workshops. The unique nature of these workshops involves a hybrid of simulation, performance and reflection, which we term "supported performance simulation". The aims differed for both student groups. The second year student nurses were given the opportunity to explore challenging ethical situations based upon "real life" practice scenarios, testing strategies to manage these in a safe, simulated environment (Table 2). The theatre studies students were enabled to investigate their understanding of performance in simulation. Theatre experience, of working with performance to enable learning in others, was used both as an exercise in itself and to better prepare theatre studies students for employment after university. We adopted a mode of working that we termed supported performance simulation, in which students were enabled to discover their own learning through reflection, then apply and extend this knowledge in practical discovery. This model was used for both sets of students. This article addresses the development of knowledge for student nurses; we will address our research with theatre students in separate work.

The workshops were based within the University simulation suite, enabling realistic ward and community environments to be created. The theatre studies students were given a set of short, written "scenarios", providing a guide to location, people, and key issues. The theatre students developed and performed initial scenes to the nurses in the group, who were asked to respond to the situation as it unfolded and guide the theatre studies students to try and resolve the situations. Later, scenarios were delivered to smaller groups of 4-6 student nurses, with theatre studies students acting the role of either a patient, family member or healthcare professional. One student nurse took the lead in each scenario, observed by their peers. They were encouraged to manage the situation independently and experiment with approaches, with opportunities throughout to pause the scenario in order to seek advice and support from their peers, then try an alternative approach. Following each situation a teacher led a broader discussion, exploring ethical issues raised and the decision making process.

With the students' permission, the workshops were filmed for review in a structured classroom session in the nursing students' final year. This allowed students to reflect upon their learning and ability to manage subsequent ethical challenges experienced in practice. In this review, the nursing students enthusiastically reported the value of the workshops in increasing their clinical confidence. Consequently, the teaching staff recognised the need to research the impact of this workshop, and the model of "supported performance simulation", as a teaching and learning method for both groups of students.

Table 2. Examples of Ethical Scenarios

\begin{tabular}{|l|l|}
\hline 1. & A parent who is trying to find out what is wrong with the child in the next bed. \\
\hline 2. & $\begin{array}{l}\text { A parent who does not speak English being asked to consent to a procedure on their } \\
\text { child. }\end{array}$ \\
\hline 3. & $\begin{array}{l}\text { A teenager who confides in a student nurse about a safeguarding situation and asks } \\
\text { the student to keep it a secret. }\end{array}$ \\
\hline 4. & A child who refuses treatment but the parents insist that the treatment is given. \\
\hline
\end{tabular}




\section{Background}

The literature reviewed identified two themes; the most effective methods of teaching ethics to nursing students and the use of simulation, particularly involving performance to support developing ethical practice.

The overarching aim of any learning and teaching style chosen within nurse education is the development of clinically excellent health professionals, able to transfer knowledge gained in theory successfully into a practice setting. Therefore it was felt that reviewing the literature examining the concept of the "theorypractice gap" was first essential. A range of journals were reviewed, including specific journals relating to simulation in healthcare such as Clinical Simulation in Nursing, Advances in Simulation and Simulation in Healthcare. However, this project was not simulation as such, it was a synergistic activity between two, on the surface, disparate, groups of students. The articles reviewed in these journals, although interesting, did not fully reflect that the essence of this project was.

The literature suggested a range of approaches aimed at solving the ongoing issue of the "theory-practice gap", which have been discussed since the very early days of nurse education (Briggs 1972). The healthcare environment and student nurse preparation have radically altered over time, yet the theorypractice gap persists.

One proposed solution is problem-based learning (PBL). Applin et al. (2011) suggested that PBL allowed contextualisation of learning, thus better meeting the needs of professional practice as the learner is working towards solving, or at least understanding, the "problem", going some way to closing the gap.

Levett-Jones (2007) and Michau et al. (2009) argued that practice does not necessarily ensure students will become clinically competent or learn. Michau et al. unsurprisingly found the quality of placement was key, poor clinical placements had a detrimental effect on the students' ability to become clinically competent and integrate theory and practice. In response, their educational institution introduced "real time/life scenarios" and case-based learning to help the students bridge the theory-practice gap. Additionally Hatlevik (2012) and Kalaitzidis and Schmitz (2012) argued that the key to students seeing coherence between theory and practice is developing skills of reflection.

With the theory-practice gap continuing and recognised as detrimental to students' learning and development as practitioners (Hatlevik 2012), various solutions, from reflection to PBL have been proposed. Although not discussing simulation as a solution specifically, the literature suggests that approaches that enhance a student's opportunity to embed their learning in clinical contexts are effective. Therefore what we term supported performance simulation could provide an effective bridge to the gap. By supported, we refer to a combination of strategies to enable students to apply previously acquired knowledge and experience to a specific, pressured moment of simulated practice. In our case, this included the presence of a teacher with each group, a small peer-group of nurses who were able to support and advise each nurse in their contribution to a scene, and by allowing the nurse or peers to stop a scenario at any time and discuss possible actions to take. 
When examining the benefit of simulation, as a learning style, to aid the closure of the theory-practice gap, interestingly research (Darcy Mahoney et al. 2013, Odell and Barta 2011, Akhtar-Danesh et al. 2009) focuses solely on the benefits of developing clinical cue recognition and psychomotor "skills"; leading to improved patient safety, therefore better clinical outcomes. However, we also need our newly qualifying nurses to be competent in an additional set of "softer", less clinical skills. Nurses must be excellent perceptive communicators, articulate in the moment and able to steer a relatively safe path through potential difficulties (Nursing and Midwifery Council 2015). Nurses must demonstrate, as well as feel compassion, negotiate with colleagues and the public, reason clearly and quickly, and be assertive, having confidence to present informed conclusions. Such skills enable nurses to become patient advocates and provide ethically sound individualised patient- and family-centred care; the importance of which is clearly recognised within National recommendations (The Mid Staffordshire NHS Foundation Trust 2013).

The research examining the benefit of simulation in developing "softer skills" is currently limited. One study (Eggenberger and Regan 2010) recognised the potential benefit of using simulation to teach nurses to care and to develop sound nurse-family relationships. Utilising a framework to support family nursing, students undertook simulated total care scenarios, with actors playing family members. These scenarios were filmed and later reviewed against a framework to investigate how students communicated in practical situations. Findings showed while theoretical knowledge of the skills needed to provide clinical nursing "care" was sound, students were not all able to demonstrate this in practice. The study concluded, as with the development of psychomotor skills, communication and "family nursing" skills also require practice in safe environments.

Theatre practices are already familiar constituents of simulation (Sanko et al. 2013). Our aim in this project was to enable students in nursing and theatre to practically investigate and extend their knowledge and understanding of simulation and performance in practice. The workshops allowed students to recognise and build on existing ideas and practice. Previous projects have addressed similar territory. Within Mental Health nursing, Wasylko and Stickley (2003) used "forum theatre" to support the development of humanistic skills and attitudes. Forum theatre was developed by Boal (1985), as a form of revolutionary practice that encouraged people to move from the relative ease of proposing "evolutionary and heroic acts" to the more difficult task of practicing such acts. In Boal's (1985) forum theatre, "spectators intervene directly in the dramatic action and act". While not strictly forum theatre, our work drew on aspects, particularly taking account of this revolutionary aspect of Boal's work. Given recent public and professional unease over particular instances of nursing practice, it may be that revolutionary action is not entirely unwelcome in this context.

Forum theatre was found to be a valuable tool in the development of empowerment, empathy and reflection in mental health care (Wasylko and Stickley 2003). Keltner et al. (2011) recognized the benefits of actors within simulation in developing competence to cope with the "real-world pressures" health-care workers face. Utilising actors in simulation was seen to be valuable 
in teaching and supporting students to manage emotional and stressful scenarios, such as breaking bad news, or supporting a parent following the death of a child (Keltnet et al. 2011). In their own way, such cases are themselves revolutions of a very personal kind, in which individuals' worlds are upturned, and to which nurses will need to attend. If nurses are able to test out their role in supported performance simulation, they may be far more prepared to manage such revolutions in professional practice.

Our work on this project is underpinned by our collective interest in understanding the issues and practices of simulating complex scenarios, here focusing on ethical scenarios. Simulation is a particularly useful tool to enable student nurses to think critically about complex ethical decision-making situations, reflecting modern healthcare (Gropelli 2010). The benefit of teaching ethical principles through simulation derives from the immersive nature in which the student has to evaluate a situation, think critically, and act. Simulation is far from being a solo project and, instead, it actively encourages nurses to reflect on the actions of others, enabling peer support, learning and reflection in and after taught sessions.

Finding effective methods of teaching ethics to student nurses has become a critical issue internationally. Studies have been conducted worldwide (Kalaitzidis and Schmitz 2012, Numminen et al. 2009, Numminen et al. 2011, Akram et al. 2013, Lin et al. 2010) identifying the importance of active involvement by students in the teaching of ethics, with many recognising that problem based learning is an effective way of doing this (Numminen et al. 2009, Akram et al. 2013, Lin et al. 2010). Yet, most authors recognise that there is a lack of consensus on the most effective method of teaching ethics.

Numminen et al. (2009) examined the perspectives of 183 nurse educators and 212 nursing students regarding teaching ethical codes. Students viewed traditional lectures as "dull" and preferred role-play, discussion and teamwork, whereas the educators recommended the use of the students' own clinical experiences as valuable material for teaching. Students identified the importance of having time to reflect on their experiences in practice, within the safety of the classroom setting. Chiou-Fen Lin et al. (2010) also identified the value of utilising students' own experiences and of using non-conventional methods of teaching.

Kalaitzidis and Schmitz's (2012) research on 144 undergraduate student nurses explored their perceptions of being taught ethics in nursing. Echoing Gropelli (2010), students valued the opportunity to reflect on their practice in class, with Kalaitzidis and Schmitz (2012) recognising that emotions play a significant part in ethical practice and that a period of reflection can be helpful.

Tschudin (2010) argues that there is growing appreciation of ethically based nursing. As the quality of care is often judged by the public in terms of compassion, it is important to consider how we, as educators, can best help our students to learn to address the challenges they will face in practice. Following the recommendations of Francis (The Mid Staffordshire NHS Foundation Trust 2013) it is evident that the responsibility for developing caring, compassionate, ethically aware practitioners begins in healthcare education, where teachers 
must facilitate the development of students' broader caring skills, including the ability to deal with complex ethical situations.

It cannot be assumed that nurses will simply find their way to the kind of care that we expect to take place in our care settings, but instead our responsibility as nurse educators is to guide, empower and inspire our student to learn from the lessons of the past in order to transform future care. Our project is grounded in a clear sense that there are ways in which we can, and must, enhance the capacity of nurses to both understand and to lead the delivery of patient care. Importantly these skills are not always inherent, developing naturally, but instead can, to some extent, be taught or at least honed, if students are given best opportunities.

In developing this project, we sought to address critical issues in enabling students to explore ethics through implementing our model of supported performance simulation and saw simulation as a solution to the pressing need for effective opportunities to encounter ethical scenarios in preparation for professional practice, whether that is in nursing, the arts or even in combination.

\section{Aim and Objectives}

With the aim of the study being to explore the experiences of all participants, following their involvement in the ethical workshops, the objectives of the study were as follows:

1. To explore with the child nursing students their perception of how, or if, their experience of this method of teaching ethics had impacted on their performance in practice

2. To investigate with the theatre studies students their perception of how the experience contributed to their knowledge and practice of performance and how it might inform their future development

3. To consider staff members' professional understanding of the value of this model of simulation practice, and the potential for development

\section{Research Design}

The research was located within the interpretive paradigm as our focus was the experiences of students and teachers in the project. An illuminative evaluation approach (Parlett and Hamilton 1972) was adopted, which enabled the researchers to draw on the richness of the experiences of the three specific groups involved; theatre studies students, nursing students and teachers, without using pre-determined categories or themes to limit the focus.

\section{Participants and Research Context}

Structured activity-based focus groups, based on Parlett and Hamilton's work (1972), were used for the nursing students. This involved progressive focusing, moving from general topic areas to specific points raised by the facilitator. The staff focus group employed broad questions to elicit their views on the value of the 
workshops as an educational tool. The focus groups and the interviews were facilitated by a senior researcher, one year after the workshop and 3 months after a reflective session.

A purposive sample was used, consisting of students and staff who had experienced the workshops. Of a total population of third year undergraduate child nursing students numbering 30, 19 volunteered to take part. The high percentage $(63 \%)$ prepared to volunteer could be indicative of the students' enthusiasm about the project. The total number of theatre studies students involved in the project was much lower and of these, 10 were interviewed. One reason for the lower number of respondents was that the data collection period coincided with a period of leave for the theatre studies students. All 4 of the staff members involved in the project took part in a single focus group, which allowed a rich exploration of educational philosophies and experiences.

Data collection for the child nursing students took place in focus groups and with a facilitator and note taker present. Students were asked to undertake specific activities in order to generate the data. The first activity involved the students recording on sticky-notes their individual responses to the following question: "What stands out/what do you remember about your experience of the_ethical scenarios?" They then discussed their responses in small groups to identify common themes and eliminate duplication. The second activity was a "round robin", which involved groups writing answers on flipcharts to 4 questions:

A. What did you learn (knowledge and skills)?

B. What did you learn about yourself and others?

C. What have you been able to apply in practice so far (if anything)?

D. Compared to other elements of the programme how important and valuable was this learning experience?

This was followed by a plenary discussion, based on the questions, "What worked well in relation to the organisation of the ethical scenario teaching?" and "What would you change?". The interview questions for theatre studies students mirrored the focus groups held for the nursing students, asking broadly "What stands out/what do you remember about your experience of the ethical scenarios?". This was followed by the more specific questions, as shown above. The staff focus group discussion was based on the broad questions:

A. What stands out from the collaboration and the experience of implementing the initiative?

B. What were the purposes of the initiative (individual perspective)?

C. What have you learned from the experience?

D. How valuable was the experience to students? What did they learn?

In terms of rigor, all of the data was collated and initially analysed by the senior researcher who was not part of the project team. The data was organised under the question headings that had been used and inductive thematic analysis of the responses was undertaken. This initial analysis was then shared with the staff in the team and further analysis was undertaken. 


\section{Ethical Considerations}

Favourable ethical approval was gained from the University Ethics Committee prior to the research being undertaken. Informed consent was gained from all participants.

\section{Findings}

Data from all three groups was collected and analysed. The findings within the theatre studies interviews generated themes that were specific to the educational development needs of that group, focusing upon areas such as the form of performance practice and how the work may inform future career plans.

Analysis of the nursing student and teaching staff focus groups identified the following themes:

- The value of "real world" experience.

- Increased confidence in dealing with ethically challenging situations.

- Development of "softer" skills, compassion, communication and supporting self and others to deal with emotional responses.

- Teaching and learning styles and approaches to reflective practice.

\section{The Value of "Real World" Experience}

The importance of a realistic experience was identified by students and teachers. The students, in particular, focused upon their sense of authenticity and of how scenarios related to their recent experiences of practice.

One student commented that the workshop had made her particularly "aware" of ethics, another explained the experience had "allowed me to reflect upon my actions as the event was realistic". The realism of emotional responses was also identified within the scenarios: "I could really put myself into the scenario, with their acting, the scenes were very realistic, [it] felt like hard work as if happening on the ward". Another student reflected, "it actually felt like the emotions, situation, pressure and relief were real". Several spoke about how working with theatre studies students increased the validity for them, "the actors made it harder for us, as they had little [healthcare] knowledge, as parents might". It was also identified that not knowing the theatre studies students enhanced realism, with a number of similar comments that it was "good that we didn't know the drama students, [it] made it more real".

From the perspective of teaching staff, reality was discussed in terms of behavioural responses seen in the students. One suggested that scenarios produced "very different behaviour [to that in usual sessions], professionalism ... students taking risks and being supportive". The group also highlighted the benefits of the project as being "a way of making ethics real for students" and "making links to the real world ... beyond a workshop in a room". 


\section{Increased Confidence in Dealing with Ethically Challenging Situations}

A number of the nursing students explained that the sessions had increased their confidence, especially when dealing with ethically challenging situations. This appeared to result from both active participation in the scenarios and observation of peers. Students stated "the ethical scenarios made you think about how you would deal with this even if you were not directly involved". Confidence in patient advocacy was identified, with one student stating they had found the "confidence to actually speak out in difficult situations ... I questioned practice that I thought was incorrect". Another identified "learning what to do to prevent possible situations and notice warning signs" as a result. The workshops appeared to aid students' reflection upon how much knowledge they already held, yet had not been consciously aware of. They suggested the project "gives you more confidence in what you know" and that it is "reassuring that you know what to do". Following the workshop, one student felt that it "matters what I think even as a student ... my opinion is valid".

Less positive comments included one student who thought the whole day was very "challenging". Another said that she had felt helpless when "I couldn't and wasn't sure how to calm a parent down". It was clear that students were apprehensive before the workshops, however, when later reflecting upon this, 12 students commented they felt the experience was not as scary as they had thought it would be, in comparison to four students who believed that it was "scary to be the one put on the spot". Students responded differently to the presence of a peer group of nursing students, whom they could turn to for advice. Most agreed this support helped their confidence, although four students reported that they felt empowered by being able to act alone.

One student believed they would not be able to transfer the skills practiced in the workshop into professional practice, yet the majority (11) thought that the experience gave them good insight into situations that do happen and that it was a good way to prepare for pressured situations in real life.

Teaching staff noted increased confidence as a particular benefit of the work, commenting that they saw the development of "real confidence, especially during the subsequent feedback session the following year, where nursing students were better able to relate ethical themes to practice".

Development of "Softer" Skills: Compassion, Communication and Supporting Self and Others to Deal with Emotional Responses

When asked by the facilitator what skills the students felt they had learnt, all nineteen identified communication skills. Specifically identifying listening skills; one student reflected they had learnt the benefit of "backing off, stepping back, rather than needing to talk and push". Another agreed, explaining they learnt when to talk and when to listen. The students discussed interpersonal skills needed to deal with challenges such as presenting their own ideas, particularly when these conflict with those of others. They linked this to good advocacy and being proactively assertive in their approach. Students recognised that 
some usually quiet students were able to "step into role and perform really well when needed to professionally" or "stand up for what they believed in".

When asked what practices they had been able to apply so far, the majority felt more able to speak out and question practice they felt was incorrect. The students believed that they had learnt how to question and challenge without being confrontational. One now "took actions to support children that they wouldn't have done before", however, three students did state they had not yet felt confident enough to apply these skills in practice. While the teaching staff noted the benefits of confidence, they also identified increased courage, recognising the students as "brave for taking risks and challenging each other". When discussing the student feedback session nine months after the workshop, the teachers felt the students were strong in their ability to connect ethical themes from the workshops to specific examples of practice.

\section{Teaching and Learning Styles and Approaches to Reflective Practice}

Most of the students responded positively to the workshop format. One reflected that "teaching ethics in a scenario way makes it easier to understand ethics, rather than sitting in a lecture hall". Other words used included "fun", "engaging" and "thought-provoking". Some students were able to link the experience to their preferred learning style, identifying that the workshops were more suited to a practical learning style (8 respondents); suited a kinaesthetic learning style (4 respondents). One student responded, "essays do not make a good nurse - need practical", to which 12 others agreed.

When invited to reflect on alternative methods to deliver similar content, one student noted that they could,

"sit back and read scenarios, but being thrust into them takes away the option to back away, [you] have to actually think and decide. In practice you don't have the option to engage or not, having to engage is good".

Five students actively agreed with this comment, all students agreed with the statement that the workshop provided, "a practical situation for us to think about how we would react in situations, rather than just talking about it in theory". The group consensus was that powerful emotions helped learning and that those most involved "got most from it".

The use of drama was raised, with some comments such as "too dramatic" and "contrived" (4 students). However, in exploring this further, the majority (13) believed that this approach was "necessary" in order to engage and involve them. Some individuals felt it was hard to partake in something that was not real, however 11 students actively disagreed with this perspective. Other concerns noted included 2 feeling nervous about being filmed, which had been done to allow later reflection on the work, but 10 disagreed. Other individuals expressed concerns such as anxiety at being evaluated and the need to make a good impression. One stated that she was "not an actress, I'm a nurse", however another respondent agreed that in the short term "there are bits you hate, awkward and embarrassing, but looking back all good". 
The teachers saw the experience as a powerful tool to aid reflection, and as a way of facilitating learning rather than teaching. They remarked that the students worked well together across the disciplines, forging knowledge for everyone.

The teachers had consciously left considerable time pass between the workshops and reflection, to allow students to test their learning in practice and then report back. Students had clear memories of details from the workshop. When reflecting on ethical teaching within the programme one "remembered more about that session a year ago than a recent lecture", as they were "still able to imagine and visualise how people did things a year later".

\section{Discussion}

The findings revealed a number of expected and unexpected outcomes. The explicit aim of the ethics workshops was to allow second year child field nursing students the opportunity to explore challenging ethical situations, based upon "performed simulations" of realistic practice and to test strategies to manage these in a safe environment. An unexpected outcome was the importance of this method in facilitating the development of key "softer" skill such as communication and, particularly, listening, as a critical tool.

In contrast to traditional teaching methods, which utilise student peer group role play, supported by nursing teachers in role; the use of theatre studies students outside the nursing students' normal peer group, enabled the development of more realistic environments. Supporting previous research (Wasylko and Stickley 2003, Keltnet et al. 2011, Nicholson 2015), these findings proved to be more akin to the re-enactment of real-world provided by theatre performance. Nicholson (2015) argues that an "imaginary world" in a drama workshop can allow participants to "share models of professional practice". As a learning and teaching method, this enabled memorable, committed engagement by the students, thereby enhancing their understanding and learning. Major benefits of this project were that students recognised the workshops allowed them to become more confident and, in the view of the teachers, more courageous. Secondly, the work enhanced their understanding of ethical principles in practice, in ways that they themselves were able to clearly and specifically identify a year later.

Although development of communication skills could be viewed as a desirable outcome when utilising simulated practice, the value that students placed on this experience for developing "softer" skills was unexpected. For ethically sound nursing practice, these softer skills are vital as communication, advocacy and assertiveness underpin excellent practice. Students recognised that the opportunity to practice and to develop these skills was essential, supporting Eggenburger and Regan's (2010) assertion that competence is best developed through "protected" practice. The surprises was the degree to which students recognised the importance of listening, assimilating, taking in the full picture and noting any signs that might escalate in ethically challenging situations. The teachers noticed that this self-aware reflection developed from both the opportunities provided by watching their peers, as much as the benefit achieved from direct involvement in the scenario. 


\section{Conclusion}

The results from the study identify that this set of performed simulation workshops enabled individual undergraduate child nursing students to discover, test and reflect on their own individual practice and that of their peers in an environment in which most felt secure. The development of "supported performance simulation", a hybrid of simulation, performance and reflection, proved to be a powerful method of achieving this outcome. As students recognised a year later, that, in part, was a direct result of activities in the workshops. They had demonstrated they had the confidence to address difficult situations and trust that their voice as valid, if not vital in their role as advocate.

Within all of this work, we can trace the six "C"s (Department of Health 2012). In the moment of a scenario and in reflection a year on, it was clear that students had not neatly learned these terms by rote. It was apparent how students might develop, test and reflect on an increasingly nuanced understanding of these constructs, whether as individual terms or, more likely for professional practice, in complex and forever shifting combinations. The more we can build such nuanced, embodied, memorable and applicable learning into nurse education, the more our future nurses will be empowered to engage in and thereby influence and impact on patient care directly in powerful and compelling ways.

These findings convince us that, by developing rich, transformative models of simulation, we can help prepare students for the complexity of clinical decision making required in practice. As a result, our interest has been in attending to the ways in which we might combine performance and simulation to address and attend to professional development and the need for a broader revolution in nursing care (The Mid Staffordshire NHS Foundation Trust 2013). Our collaboration to date suggests there are very clear benefits to developing, testing and refining theories and practices of engaging with ethical challenges in "supported performance simulation" as a continuing dialogue between staff and students in theatre and nursing.

The overarching aim of any learning and teaching design in nurse education is to promote a method that best supports the development of excellence in clinical nursing practice. The authors believe that the overwhelming measure of success for this project is the students' own identification, at the point of reflection one year on, of the ways in which the workshops had directly supported their increased clinical confidence and competence when managing ethically challenging situations in clinical practice. 


\section{References}

Akhtar-Danesh N, Baxter P, Valaitis RK, Stanyon W, Sproul S (2009) Nurse Faculty Perceptions of Simulation Use in Nursing Education. Western Journal of Nursing Research 31(3): 312-329.

Akram H, Seyyed-Hassan A, Sadegh-Ali T, Valliollahe A, Mohammad-Reza G, SeyyadMajid MM et al. (2013) Teaching medical ethics: problem-based learning or small group discussion? Journal of Medical Ethics and History of Medicine 6(1).

Applin H, Williams B, Day R, Buro K (2011) A comparison of competencies between problem-based learning and non-problem-based graduate nurses. Nurse Education Today 31(2): 129-134.

Boal A (1985) Theatre of the oppressed 1974 (Translated by McBride CA, McBride M-OL). New York: Theatre Communications Group.

Briggs A (1972) Report of the Committee On Nursing. London, Stationery Office.

Darcy Mahoney AE, Hancock LE, Iorianni-Cimbak A, Curley MAQ (2013) Using highfidelity simulation to bridge clinical and classroom learning in undergraduate pediatric nursing. Nurse Education Today 33(6): 648-654.

Department of Health (2012) Compassion in practice: Nursing, Midwifery and Care Staff, our vision and strategy. London: Stationery Office.

Eggenberger SK, Regan M (2010) Expanding simulation to teach family nursing. Journal of Nursing Education 49(10): 550-558.

Gropelli TM (2010) Using active simulation to enhance learning of nursing ethics. Journal of Continental Education Nursing 41(3): 104-105.

Hatlevik IKR (2012) The theory-practice relationship: reflective skills and theoretical knowledge as key factors in bridging the gap between theory and practice in initial nursing education. (Report). Journal of Advanced Nursing 68(4): 868-877.

Kalaitzidis E, Schmitz K (2012) A study of an ethics education topic for undergraduate nursing students. Nurse Education Today 32(1): 111-115.

Keltner NL, Grant JS, McLearnon D (2011) Use of actors as standardized psychiatric patients. Journal of Psychosocial Nursing and Mental Health Services 49(5): 34-40.

Levett-Jones T (2007) Facilitating reflective practice and self-assessment of competence through the use of narratives. Nurse Education in Practice 7(2): 112-119.

Lin C, Lu M, Chung C, Yang C (2010) A comparison of problem-based learning and conventional teaching in nursing ethics education. Nursing Ethics 17(3): 373-382.

Michau R, Roberts S, Williams B, Boyle M (2009) An investigation of theory-practice gap in undergraduate paramedic education. BMC Medical Education 9: 23-23.

Nicholson H (2015) Taking Time. Research in Drama Education: The Journal of Applied Theatre and Performance 20(2): 135-138.

Numminen OH, Leino-kilpi H, Van DA, Katajisto J (2009) Nursing students and teaching of codes of ethics: an empirical research study. International Nursing Review 56(4): 483-490.

Numminen O, Leino-Kilpi H, van DA, Katajisto J (2011) Comparison of nurse educators' and nursing students' descriptions of teaching codes of ethics. Nursing Ethics 18(5): 710-724.

Nursing and Midwifery Council (2015) The Code: professional standards of practice and behaviour for nurses and midwives. Retrieved from goo.gl/BxgJld. [Accessed: 25 September 2016]

Odell E, Barta K (2011) Teaching Evidence- Based Practice: The Bachelor of Science in Nursing Essentials at Work at the Bedside. Journal of Professional Nursing 27(6): 370-377. 
Parlett M, Hamilton D (1972) Evaluation as Illumination: A new approach to the study of Innovatory Programs. Occasional Paper. Centre for Research in the Educational Sciences; University of Edinburgh.

Sanko JS, Shekhter I, Kyle RR, Di Benadetto S, Birnbach DJ (2013) Establishing a convention for acting in healthcare simulation. Simulation in Healthcare 8(4): 215-220.

The Mid Staffordshire NHS Foundation Trust (2013) Report of the Mid Staffordshire NHS Foundation Trust Public Inquiry. London: The Stationery Office.

Tschudin V (2010) Nursing ethics: The last decade. Nursing Ethics 17(1): 127-131.

Wasylko Y, Stickley T (2003) Theatre and Pedagogy: using drama in mental health nurse education. Nurse Education Today 23(6): 443-448. 